\begin{tabular}{|} 
Ambiente \& Água - An Interdisciplinary Journal of Applied Science \\
ISSN 1980-993X - doi:10.4136/1980-993X \\
www.ambi-agua.net \\
E-mail: ambi.agua@gmail.com
\end{tabular}

\title{
Mapa de aptidão do solo para a aplicação de lodo de esgoto: Bacia dos rios Piracicaba, Capivari e Jundiaí
}

\author{
doi:10.4136/ambi-agua.1714 \\ Received: 20 Jul. 2015; Accepted: 08 Dec. 2015 \\ Rodrigo Custódio Urban*; Ricardo de Lima Isaac \\ Universidade Estadual de Campinas (UNICAMP), Campinas, SP, Brasil \\ Faculdade de Engenharia Civil, Arquitetura e Urbanismo (FEC) \\ Departamento de Saneamento e Ambiente \\ *Autor correspondente: e-mail: rodrigo.urban@yahoo.com.br, \\ isaac@fec.unicamp.br
}

\section{RESUMO}

Considerando o problema técnico-econômico da disposição final de lodos gerados em estações de tratamento de esgoto, o presente trabalho teve como objetivo apresentar um mapa de aptidão do solo à recepção de lodo de esgoto da bacia dos Rios Piracicaba, Capivari e Jundiaí (PCJ). A bacia PCJ está localizada nos Estados de São Paulo (maior parte) e Minas Gerais. Caracteriza-se por apresentar grandes centros urbanos, importantes polos industriais e agrícolas, e constante crescimento populacional. Foram consideradas 6 classes de restrição da área ao uso de lodo de esgoto. Para definição das classes de restrição foram usados dados de relevo, susceptibilidade à erosão e tipo de solo, além de critérios relativos ao uso do solo, como presença de unidades de conservação, cursos d’água e áreas urbanas. Os mapas gerados demonstraram que menos de $30 \%$ do solo da bacia PCJ é apto à recepção de lodo de esgoto (conforme as classes de restrição de 0 a 3). Mesmo considerando apenas as classes de restrição de 0 a 2, foi possível observar que as áreas tem grande capacidade de recepção de

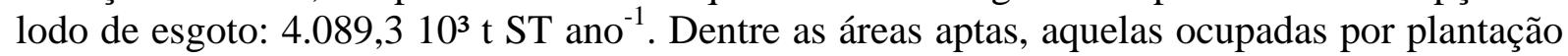
de cana de açúcar e reflorestamento foram identificadas como preferenciais à recepção. As áreas de reflorestamento aptas cobrem menos de 0,15 \% da área da bacia PCJ, mas podem ser úteis para as estações de tratamento de esgoto da parte oeste. Já as áreas cultivadas por cana de açúcar tem capacidade de recepção anual de lodo de esgoto de 2.582,7 $10^{3}$ t ST.

Palavras-chave: biossólidos, gerenciamento de lodo, resíduos de saneamento, SIG, uso do solo.

\section{Land feasibility map for sewage sludge application: watershed of the Piracicaba, Capivari and Jundiaí Rivers - Brazil}

\section{ABSTRACT}

Considering the technical and economic characteristics of the final disposal of sewage sludge, this paper sought to develop a land feasibility map for sewage sludge (biosolids) application in the watershed of the Piracicaba, Capivari and Jundiaí (PCJ) Rivers. The PCJ watershed is located in the States of São Paulo and Minas Gerais, and is characterized by large urban areas, important industrial and agricultural areas, and steady population growth. Six restricted classes of soils to receive biosolid applications were considered. The criteria 
used were susceptibility to erosion, soil type, and restrictive criteria as protected areas, water courses and urban areas. The maps generated have shown that less than $30 \%$ of the soil of the PCJ watershed is suitable to biosolids application. Considering only the classes of restriction 0,1 and 2, it was observed that the areas have great potential for biosolids application: 4,089.3 $10^{3} \mathrm{t}$ TS year-1. The sugar cane crop and reforestation areas were considered a priority to receive applications among suitable areas. Suitable reforestation areas cover less than $0.15 \%$ of the area of the PCJ watershed, but can be useful for the treatment stations of the west region. The areas covered by sugar cane have an annual sewage sludge reception capacity of $2,582.710^{3} \mathrm{t}$ TS.

Keywords: biosolids, GIS, land use, sanitation waste, sludge management, wastewater sludge.

\section{INTRODUÇÃO}

A disposição final dos lodos gerados em estações de tratamento de esgoto (ETE) urbanos é um problema crescente em regiões altamente urbanizadas. Os processos biológicos e físicoquímicos aplicados no tratamento de esgoto demandam destinação final dos resíduos sólidos gerados. O volume de lodo gerado em ETE gira em torno de $1 \%$ a $2 \%$ do volume total de esgoto tratado, entretanto, o tratamento e disposição final podem representar até $50 \%$ dos custos operacionais (Andreoli, 1999).

O gerenciamento de resíduos sólidos no Brasil teve um acréscimo de restrições legais após a publicação da Política Nacional dos Resíduos Sólidos - PNRS (Brasil, 2010). A destinação final ambientalmente correta de resíduos sólidos passa a ser um requisito para os geradores, incluindo as empresas de saneamento. Entretanto, os gestores têm dificuldades em encontrar áreas e alternativas que sejam economicamente viáveis e sustentáveis.

Andreoli (1999) considera a reciclagem agrícola do lodo de ETE como a solução mais adequada, pois reduz a utilização de recursos naturais e previne as vias inadequadas de destinação. Pesquisas ao redor do mundo indicam os possíveis benefícios do uso de lodo de ETE na agricultura: aumento da produtividade, melhora da qualidade da cultura e melhora das características físico-químicas e biológicas do solo (Andreoli, 1999; Murray et al., 2008; Singh e Agrawal, 2008; Kelessidis e Stasinakis, 2012; Lu et al., 2012). Entretanto, existem ressalvas em relação ao seu uso, para que não haja danos à saúde pública ou mesmo ao ambiente. Alguns trabalhos indicam os metais pesados, patógenos e micropoluentes orgânicos como os principais contaminantes presentes no lodo de ETE. (Pasda et al., 2006; Singh e Agrawal, 2008; Clarke e Smith, 2011; Kelessidis e Stasinakis, 2012).

Apesar da aplicação do lodo de ETE na agricultura acontecer a algumas décadas no mundo (Lu et al., 2012), a regulamentação da aplicação do lodo de esgoto no Brasil ocorre nos Estados do Paraná e de São Paulo durante a década de 1990 e no nível federal apenas em 2006 (Andreoli et al., 2008).

Os limites apresentados nas normas que regulamentam a reciclagem agrícola de lodo de ETE variam de país para país, mas, no geral, buscam a segurança sanitária desse material. Mais ou menos restritivas, as normas abrangem limites para os já citados metais pesados e microrganismos patogênicos (Beecher, 2008). Algumas normas também podem apresentar limites para a taxa de aplicação, critérios para monitoramento, controle de vetores e de emissão de odores (Lu et al., 2012).

Além da regulamentação dos limites de contaminantes permitidos, a aplicação do lodo de esgoto no solo agrícola deve considerar aspectos como a distância segura de corpos d'água e áreas residenciais, cultura recomendada para o uso e aptidão dos solos para o seu recebimento (Andreoli et al., 2001; CONAMA, 2006).

Considerando a reciclagem do lodo de ETE como uma alternativa viável, desde que as 
normas para segurança de saúde pública e ambiental sejam cumpridas, e visando facilitar a tomada de decisão dos gestores, o presente estudo tem como objetivo organizar um mapa de aptidão do solo à recepção de lodos de ETE em uma importante região do Estado de São Paulo: a bacia dos rios Piracicaba, Capivari e Jundiaí.

\section{MATERIAL E MÉTODOS}

\section{1. Área de estudo}

A bacia dos rios Piracicaba, Capivari e Jundiaí (PCJ) tem área total de 15303,67 km², sendo 92,6 \% localizados dentro do Estado de São Paulo e 7,4 \% no Estado de Minas Gerais. As bacias hidrográficas situam-se entre os meridianos $46^{\circ}$ e $49^{\circ} \mathrm{O}$ e latitudes $22^{\circ}$ e $23,5^{\circ} \mathrm{S}$ (COBRAPE, 2011).

Setenta e seis municípios estão, total ou parcialmente, dentro da bacia PCJ. Desses, 63 possuem sede administrativa dentro de áreas da bacia, totalizando uma população de 5.268.798 habitantes em 2010. A população urbana corresponde a 96,13\% dos habitantes da área. A cobertura do abastecimento de água alcança $96 \%$ na área dos municípios das bacias PCJ. A coleta de esgotos tem percentual médio de atendimento de 84,9\%. As maiores deficiências, em relação ao saneamento, são apresentadas no tratamento de esgotos, com índice médio de 41,8\% (COBRAPE, 2011).

Os usos do solo predominantes na região são o cultivo de cana-de-açúcar (33,61 \% da área) e as áreas de pastagem (39,06 \% da área). Por se tratar de uma região extensa e com relativa variação de relevo e geologia, existem vários tipos de solos na área de estudo (COBRAPE, 2011).

\subsection{Mapa de aptidão do solo à recepção de lodo de esgoto}

Para a organização do mapa de aptidão do solo à recepção de lodo de esgoto, foi adaptada a metodologia de Andreoli et al. (2000) e Souza et al. (2008), acrescentando critérios restritivos de uso do solo, considerados pertinentes ao estudo e respeitando as indicações da resolução 357 (CONAMA, 2006). A metodologia consiste na adoção de graus de restrição (0 a 5) para critérios relacionados às características do solo e de uso do solo. Mapas preliminares foram criados para cada critério, no formato de arquivo matricial. Foi realizada a sobreposição de todos os mapas elaborados, sendo atribuído a cada pixel o maior valor de grau dos critérios superpostos. O sistema de classificação é apresentado na Tabela 1. Todo o procedimento foi realizado em ambiente SIG. A base de dados foi obtida em Biociclo (2012).

A taxa de aplicação do lodo de esgoto no solo dependerá: do seu conteúdo em nutrientes, não devendo gerar aportes de nitrogênio superiores às quantidades necessárias ao desenvolvimento das culturas receptoras (Andreoli et al., 2001; CONAMA, 2006); da elevação do pH provocado pelo lodo de esgoto, que não deve ultrapassar o limite de 7,0 na mistura lodo-solo (CONAMA, 2006); e da concentração de substâncias inorgânicas, que não deverão exceder as indicações da resolução 375 (CONAMA, 2006).

Conforme a resolução 375 (CONAMA, 2006), a taxa de aplicação de lodo de esgoto depende do quociente entre a quantidade de nitrogênio recomendado para a cultura e o teor de nitrogênio disponível no lodo de esgoto. Entretanto, nem todas as ETE disponibilizam os dados de nitrogênio Kjeldahl, amoniacal, nitrato e nitrito. Por isso, para uma estimativa conservadora da capacidade de recepção, foi considerado metade do valor obtido para o solo mais restritivo estudado por Marin et al. (2010) no estado do Paraná. Foi utilizada metade do valor para considerar áreas com menor capacidade de recepção. O referido estudo utilizou o critério do poder corretivo de acidez do solo. Assim a capacidade anual de recepção considerada foi de 15 toneladas de matéria seca por hectare. 
Tabela 1. Critérios para classificação da aptidão do solo à recepção de lodo de esgoto. Critérios adaptados de Andreoli et al. (2000) e Souza et al. (2008).

\begin{tabular}{|c|c|c|}
\hline Critério & Restrição & Características \\
\hline \multirow{3}{*}{ Profundidade } & 0 -nula & Latossolos, cambissolos ou argissolos profundos. \\
\hline & 2-moderado & $\begin{array}{l}\text { Cambissolos ou argissolos com citação de pouca } \\
\text { profundidade }\end{array}$ \\
\hline & 3-forte & $\begin{array}{l}\text { Neossolos litólicos ou outras unidades com citação de solos } \\
\text { rasos }\end{array}$ \\
\hline \multirow{5}{*}{ Textura superficial } & 0 -nula & Textura argilosa (35-60 \% de argila) \\
\hline & 1 fraco & Textura muito argilosa (> $60 \%$ de argila) \\
\hline & 1-ігасо & Textura média (15-35 \% de argila) \\
\hline & 2-moderada & Textura siltosa ( $<35 \%$ de argila e $<15 \%$ de areia) \\
\hline & 3-forte & Textura arenosa $(<15 \%$ de argila) \\
\hline \multirow{5}{*}{ Susceptibilidade à erosão } & 0 -nula & Solos em relevo plano \\
\hline & 1-fraca & Solos argilosos ou muito argilosos em relevo suave ondulado \\
\hline & 2-moderada & $\begin{array}{l}\text { Textura média ou siltosa em relevo suave ondulado e textura } \\
\text { argilosa em relevo ondulado }\end{array}$ \\
\hline & 3-forte & $\begin{array}{l}\text { Relevo ondulado com textura arenosa e/ou caráter abrupto. } \\
\text { Relevo forte ondulado com textura muito argilosa }\end{array}$ \\
\hline & 4-muito forte & $\begin{array}{l}\text { Relevo forte ondulado, com textura média e arenosa. Relevo } \\
\text { montanhoso ou escarpado independente da classe textural. }\end{array}$ \\
\hline \multirow{5}{*}{ Relevo } & 0 -nula & Relevo plano (0-3 \%) \\
\hline & 1-fraco & Relevo suave ondulado (3-8 \%) \\
\hline & 2-moderada & Relevo ondulado (8-20 \%) \\
\hline & 3-forte & Relevo forte ondulado (20-45 \%) \\
\hline & 4-muito forte & Montanhoso ou escarpado (> 45 \%) \\
\hline \multirow[b]{2}{*}{ Hidromorfismo } & 0-nulo & Sem indicação \\
\hline & 3-forte & Hidromórfico \\
\hline \multirow{2}{*}{ Área de conservação } & 0-nulo & Área sem unidades de conservação \\
\hline & 5-total & Área de conservação \\
\hline \multirow{2}{*}{ Reservatórios } & 0-nulo & Área sem reservatório \\
\hline & 5- total & Reservatórios e área de 30 metros no entorno \\
\hline \multirow[t]{2}{*}{ Cursos d’água } & 0-nulo & Áreas sem rios \\
\hline & 5- total & Rios e respectiva área de preservação permanente \\
\hline \multirow{2}{*}{ Vulnerabilidade de aquíferos } & 0-nulo & Área sem recarga de aquíferos \\
\hline & 5- total & Área de recarga de aquíferos \\
\hline \multirow[t]{2}{*}{ Áreas urbanas } & 0 -nulo & Uso do solo diferente de urbano \\
\hline & 5- total & Uso do solo urbano \\
\hline
\end{tabular}

Foi adotado o maior valor dado ao pixel, independentemente do critério, como o valor do grau de restrição do solo. Pode-se classificar os solos, quanto aos critérios de restrição, conforme a lista a seguir, adaptada de Andreoli et al. (2001):

- Classe de restrição 0: Potencial muito alto para a aplicação de lodo de esgoto;

- Classe de restrição 1: Potencial alto para a aplicação de lodo de esgoto;

- Classe de restrição 2: Potencial moderado para a aplicação de lodo de esgoto. Devem ser recomendadas práticas rigorosas de conservação de solos, para a permissão do uso do 
material;

- Classe de restrição 3: Potencial baixo para a aplicação dos lodo de esgoto. Devem ser apresentados critérios atenuantes, como alternativas de manejo e práticas culturais. Se as medidas não forem efetivamente tomadas haverá risco;

- Classe de restrição 4: Não recomendada a aplicação do lodo de esgoto. Existe grave risco ao ambiente e à população no caso da aplicação do material;

- Classe de restrição 5: Restrição total à aplicação de lodo de esgoto.

\section{RESULTADOS E DISCUSSÃO}

Após a aplicação do método descrito anteriormente foi possível elaborar o mapa de aptidão para aplicação de lodo de esgoto na bacia PCJ (Figura 1).

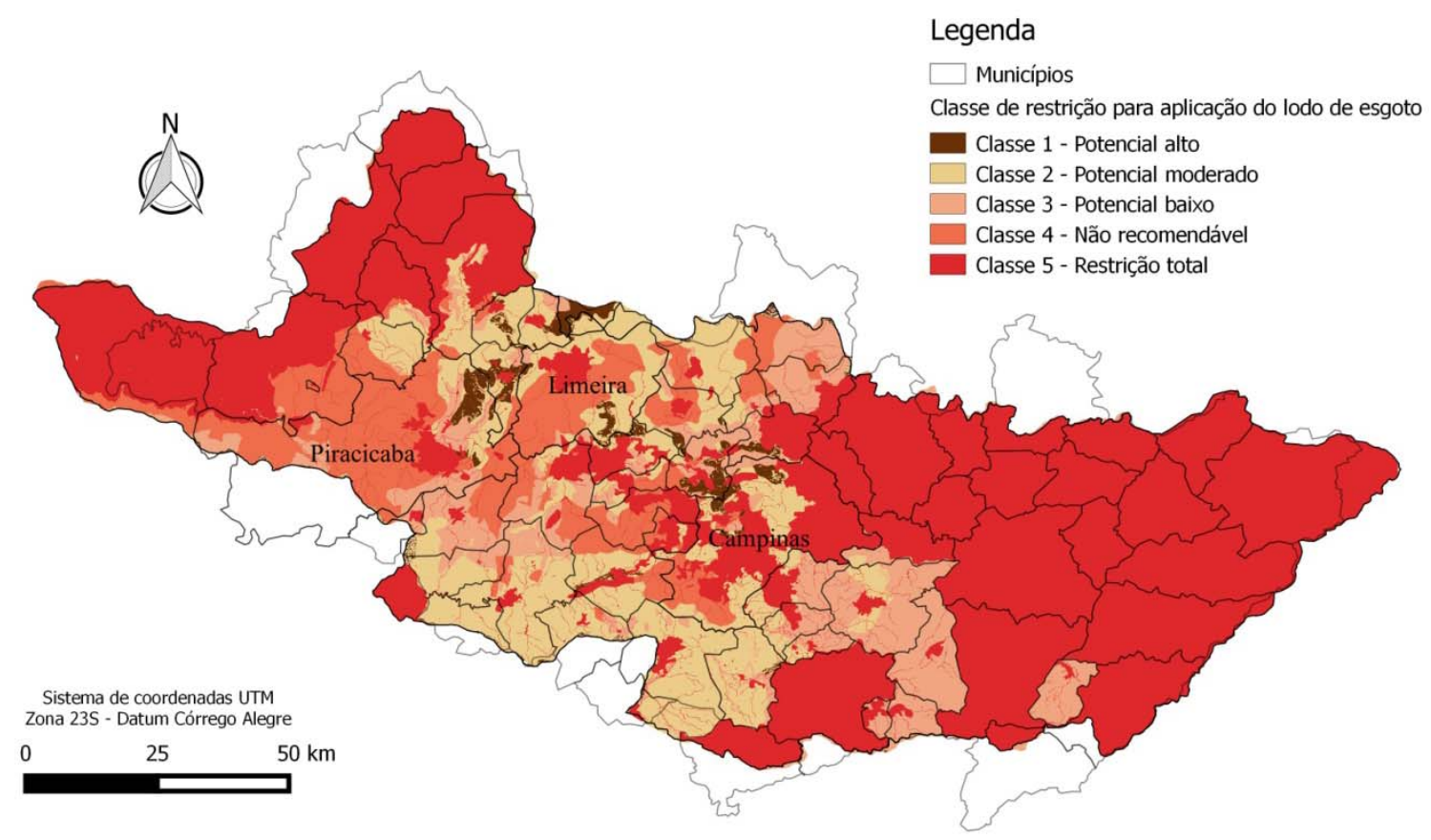

Figura 1. Mapa de aptidão do solo da bacia PCJ à aplicação de lodo de esgoto.

A partir do mapa pode-se perceber que a bacia PCJ tem grande parte de sua área proibida (classe 5) à aplicação de lodo de esgoto. Isso se deve principalmente a localização de quatro grandes áreas de preservação ambiental (APA): APA Corumbataí na parte leste da bacia, na parte oeste a APA Piracicaba - Juqueri Mirim Área 2, a APA Fernão Dias e a APA Sistema Cantareira. Enfatiza-se aqui que a resolução 375 (CONAMA, 2006) permite a aplicação de lodo de esgoto em APA, desde que estas não protejam mananciais de abastecimento. Entretanto, para evitar riscos ambientais, preferiu-se uma abordagem mais conservadora, excluindo-se todas as APA das áreas aptas à recepção de lodo de esgoto.

As áreas urbanas das grandes cidades da região (Campinas, Piracicaba e Limeira) também contribuíram para as áreas proibidas à aplicação de lodo de esgoto. É importante apontar essas cidades porque são elas também as maiores geradoras de lodo de ETE na bacia.

Não existem áreas na bacia PCJ com classe de restrição 0 , que seriam aqueles solos muito aptos a receberem o lodo de esgoto.

Conforme a lista baseada em Andreoli et al. (2001), as classes de restrição 4 e 5 não são adequadas para a recepção de lodo. Para tornar as áreas aptas mais visíveis foi feito um recorte do mapa apresentado na Figura 1. Esse novo mapa apresenta as classes de restrição 1, 
2 e 3 conjuntamente. Nessas áreas, consideradas aptas, é apresentado o uso e ocupação do solo, como última medida de restrição. A localização das ETE da bacia também é apresentada (Figura 2).

Visualmente, percebe-se no mapa, que as áreas cobertas por plantação de cana de açúcar e pastagem são predominantes nas classes de restrição 1, 2 e 3. Entretanto, a resolução 375 (CONAMA, 2006) proíbe a aplicação de lodo de esgoto em pastagem. A maior parte das ETE está concentrada nas proximidades das áreas consideradas aptas, com exceção de algumas da porção oeste da bacia PCJ.

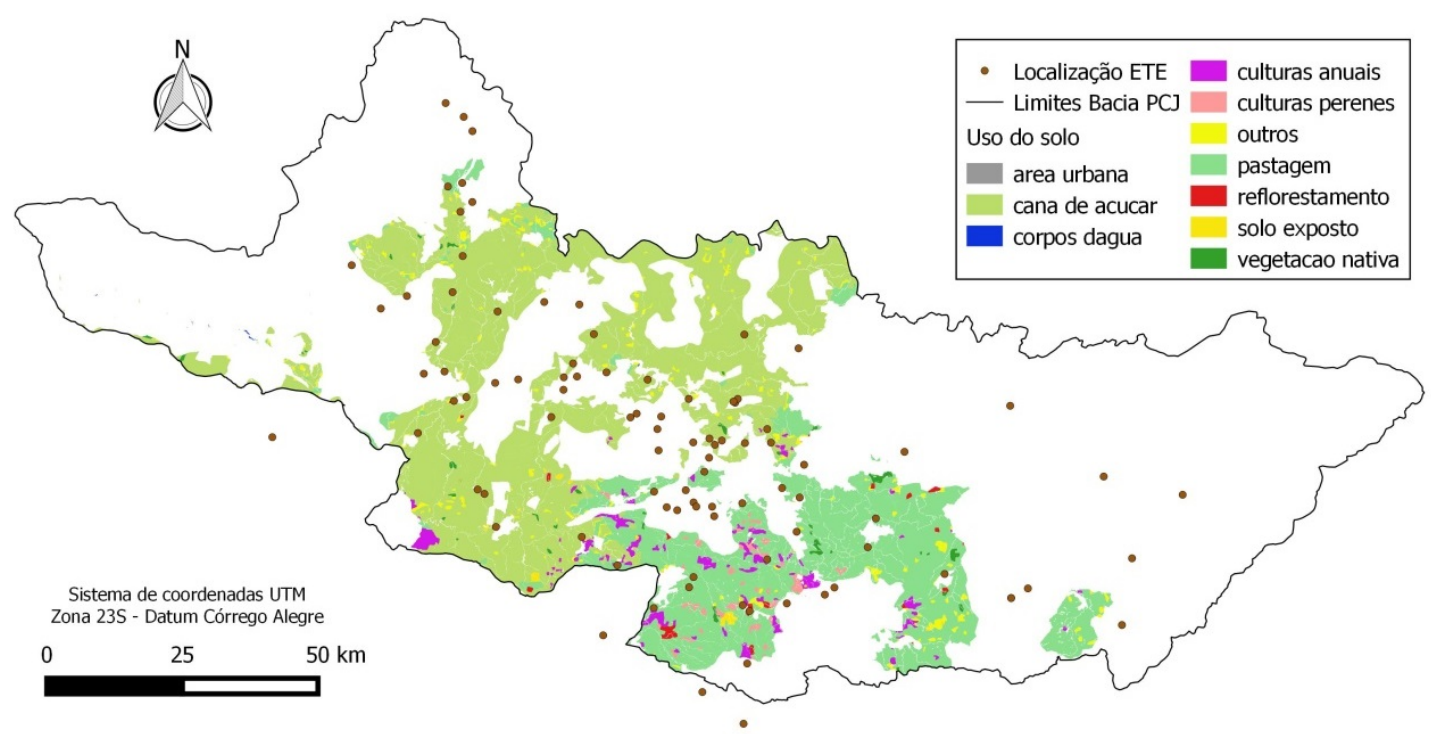

Figura 2. Uso e ocupação de áreas com classe de restrição 1, 2 e 3 à aplicação de lodo de esgoto bacia PCJ.

Entretanto, solos de classe 3 de restrição ainda tem risco de aplicação, conforme Andreoli et al. (2001). Por isso optou-se por fazer um segundo recorte, apenas com as áreas de classe 1 e 2 de restrição. Novamente as ETE foram representadas no mapa gerado (Figura 3).

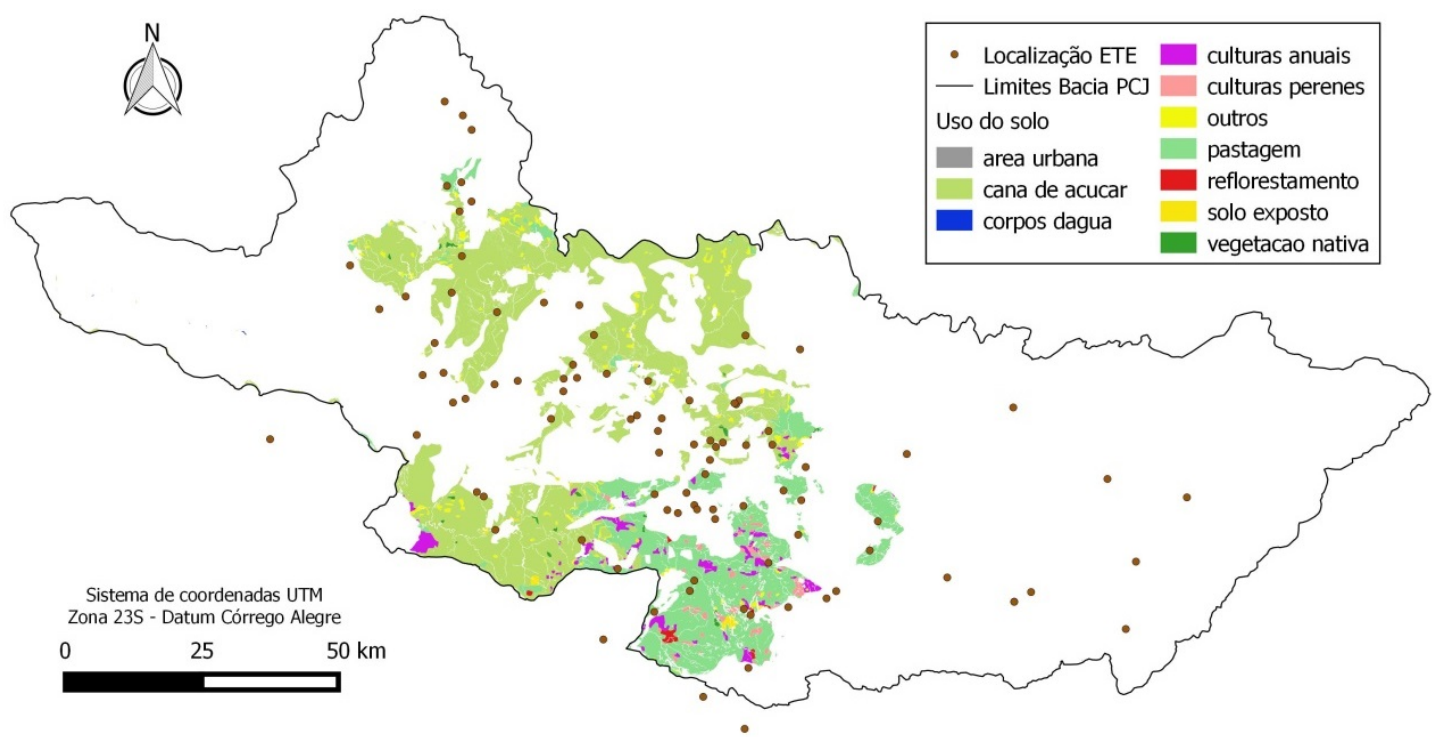

Figura 3. Uso e ocupação de áreas com classe de restrição 1 e 2 à aplicação de lodo de esgoto - Bacia PCJ. 
A análise do mapa permite observar que a área disponível para a aplicação do lodo de esgoto diminui consideravelmente com a retirada dos solos de classe 3 de restrição. As ETE da porção oeste da bacia ficam agora mais distantes dos possíveis pontos de aplicação, o que acarreta custos maiores com transporte para a disposição final.

Para confirmar as análises visuais realizadas, foram extraídas as áreas dos polígonos que caracterizam o uso e ocupação do solo das áreas com as classes de restrição 1, 2 e 3. Os valores percentuais em relação à área total da bacia PCJ são apresentados na Tabela 2.

A análise da Tabela 2 permite afirmar que a ocupação de cana de açúcar e pastagem é predominante em toda a área apta à recepção de lodo de esgoto. Novamente enfatizando a proibição da aplicação em pastagem pela resolução 375 (CONAMA, 2006). A classe de restrição 1 representa menos de $2 \%$ do total da bacia, apresentando pouca opção de área receptiva. A classe de restrição 2 cobre área maior que a classe de restrição 3, e deve ser usada prioritariamente, quando as áreas de classe 1 não estiverem disponíveis.

Menos de 30\% da área da bacia PCJ é apta à recepção de lodo. Esse valor diminui para menos de $17 \%$, quando considerados apenas as classes menos restritivas (1 e 2). Entretanto, a capacidade de recepção de lodo dessas áreas pode ser considerável.

Para a análise da capacidade de recepção, estimou-se que cada hectare poderia receber 15 toneladas de lodo de esgoto por ano, vide metodologia. Considerando as porcentagens da área total, tem-se uma capacidade de recepção anual, conforme a Tabela 2.

Tabela 2. Porcentagem da área ocupada e capacidade de recepção de cada uso do solo em relação ao grau de restrição à aplicação de lodo de esgoto.

\begin{tabular}{lccccccr}
\hline \multirow{2}{*}{ Classe } & \multicolumn{7}{c}{ Uso (\%) } \\
\cline { 2 - 8 } & Cana de açúcar & Culturas anuais & Culturas perenes & Pastagen & Reflores. & Outros & Total \\
\hline 1 & 1,42 & 0,01 & $<0,01$ & 0,11 & $<0,01$ & 0,06 & $\mathbf{1 , 5 9}$ \\
2 & 9,83 & 0,53 & 0,24 & 4,94 & 0,08 & 0,61 & $\mathbf{1 6 , 2 2}$ \\
3 & 5,96 & 0,17 & 0,03 & 5,24 & 0,06 & 0,54 & $\mathbf{1 2 , 0 0}$ \\
\hline Total & $\mathbf{1 7 , 2 1}$ & $\mathbf{0 , 7 0}$ & $\mathbf{0 , 2 7}$ & $\mathbf{1 0 , 2 8}$ & $\mathbf{0 , 1 4}$ & $\mathbf{1 , 2 0}$ & $\mathbf{2 9 , 8 1}$ \\
\hline \multicolumn{7}{c}{ Capacidade de recepção do uso $\left(10^{3}\right.$ t) } \\
\hline 1 & 325,9 & 1,2 & 0,7 & 24,6 & 0,1 & 13,0 & $\mathbf{3 6 5 , 5}$ \\
2 & $2.256,8$ & 121,1 & 54,6 & $1.133,2$ & 18,0 & 140,1 & $\mathbf{3 . 7 2 3 , 8}$ \\
3 & $1.367,1$ & 39,0 & 7,3 & $1.202,5$ & 14,5 & 123,1 & $\mathbf{2 . 7 5 3 , 6}$ \\
\hline Total & $\mathbf{3 . 9 4 9 , 8}$ & $\mathbf{1 6 1 , 3}$ & $\mathbf{6 2 , 6}$ & $\mathbf{2 . 3 6 0 , 3}$ & $\mathbf{3 2 , 6}$ & $\mathbf{2 7 6 , 3}$ & $\mathbf{6 . 8 4 2 , 9}$ \\
\hline
\end{tabular}

A classe de restrição 1, mesmo ocupando menos de 2 \% da área da bacia, ainda é capaz de receber 365,5 mil toneladas de lodo de esgoto anualmente. Com esta capacidade seria possível receber o equivalente ao lodo produzido por 7,5 cidades do porte de Curitiba, conforme dados apresentados por Pegorini et al. (2003).

Deve-se observar, assim como as pastagens, que nem todos os usos do solo representados podem receber o lodo de esgoto, apesar de serem considerados aptos. A resolução 375 (CONAMA, 2006) indica que, além da pastagem, a aplicação de lodo de esgoto é proibida em "cultivo de olerícolas, tubérculos e raízes e culturas inundadas, além de outras culturas cuja parte comestível entre em contato com o solo". Se houver a necessidade de cultivar as culturas citadas deve-se respeitar o prazo de 4 anos da última aplicação de lodo de esgoto. Isso acaba inviabilizando a aplicação nas culturas anuais ou mesmo nas perenes.

Andreoli et al. (2001) recomendam a aplicação de lodo de esgoto em "grandes culturas cujos produtos são industrializados ou não são consumidos in natura". Dessa forma, pode-se inserir nessa definição as áreas de cana de açúcar, que são aquelas que têm maior capacidade 
de recepção de lodo de esgoto (mais de $3.90010^{3}$ t ST ano ${ }^{-1}$ ). Conforme os mesmo autores, também é viável a aplicação em reflorestamento. Essa opção deve ser considerada, apesar de ocupar menos de 0,15 \% da área da bacia PCJ, pois pode ser um destino para as ETE que se encontram na parte oeste da bacia, e mais distantes das áreas de cana de açúcar. Os usos citados não desrespeitam as indicações da resolução 375 (CONAMA, 2006).

Considerando apenas as classes de restrição do solo que permitam a aplicação de lodo de esgoto, restringiram-se as áreas de plantação de cana de açúcar e reflorestamento para a recepção de lodo. Juntas essas áreas ocupam 17,36 \% da área total da bacia PCJ, e tem

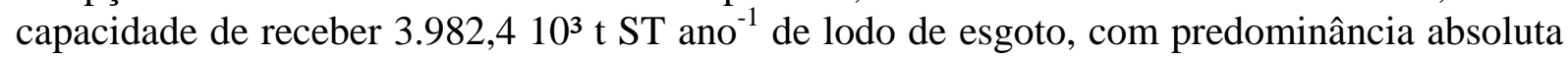
das áreas com cana de açúcar.

Excluindo a classe de restrição 3, pois demanda maior cuidado para a aplicação do lodo de esgoto, as áreas de cana de açúcar da bacia PCJ passam a ter capacidade de recepção de

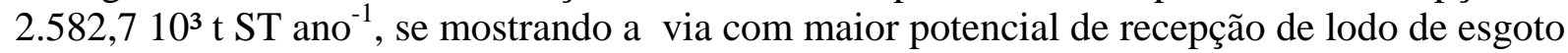
na área de estudo.

Uma importante ressalva sobre o uso das áreas de pastagem para a aplicação de lodo de esgoto deve ser feita, devido à possibilidade de receber pouco mais de $2.300 \mathrm{mil} \mathrm{t} \mathrm{ano}^{-1}$. Apesar de proibida a aplicação direta, existe a possibilidade de aplicação do lodo de esgoto e posterior implantação da pastagem. Entretanto, a entrada de animais deve ocorrer após 2 anos da última aplicação do lodo de esgoto (CONAMA, 2006), tornando essa opção pouco viável.

\section{CONCLUSÃO}

A metodologia adaptada para a elaboração do mapa de aptidão do solo à aplicação de lodo de esgoto da bacia PCJ se mostrou coerente e aplicável. O mapa gerado para a área de estudo pode ser usado como consulta auxiliar na tomada de decisão dos gestores das empresas de saneamento da bacia. A metodologia pode ser utilizada em outras áreas, desde que sejam consideradas, e incluídas nos critérios, as especificidades legais regionais.

Recomenda-se a aplicação do lodo de esgoto nos solos cultivados com cana de açúcar e reflorestamento. Considerando os usos citados e apenas as duas menores classes de restrição, 11,33\% da área da bacia PCJ é considerada apta à recepção de lodo, com uma capacidade estimada de recepção de 2600,8 mil t ST ano-1 ${ }^{-1}$ conforme o critério de limitação da quantidade de lodo pela alteração do $\mathrm{pH}$ do solo.

Os mapas apresentados são de abrangência regional, e devem ser usados em uma avaliação preliminar dos locais aptos à recepção. Estudos complementares devem ser realizados para a seleção dos locais específicos para a aplicação do lodo de esgoto de cada ETE. Para cada local escolhido deve-se fazer o cálculo da capacidade de recepção anual, considerando as características específicas do lodo da ETE e do solo onde este será lançado.

\section{REFERENCIAS}

ANDREOLI, C. V. (Coord.). Uso e manejo do lodo de esgoto na agricultura. Curitiba: SANEPAR $\backslash$ PROSAB, 1999.

ANDREOLI, C. V.; PEGORINI, E. S.; CASTRO, L. A. R. Diagnóstico do potencial dos solos da região de Maringá para a disposição final do lodo gerado pelos sistemas de tratamento de esgoto do município. Sanare - Revista Técnica da Sanepar, v. 13, n. 13, p. 40-50, 2000.

ANDREOLI, C. V.; PEGORINI, E. S.; FERNANDES, F. Disposição do lodo no solo. In: ANDREOLI, C. V.; VON SPERLING, M.; FERNANDES, F. (Eds.). Lodo de esgotos: tratamento e disposição final. Belo Horizonte: UFMG; SANEPAR, 2001. 
ANDREOLI, C. V.; GARBOSSA, L. H. P.; LUPATINI, G.; PEGORINI, E. S. Wastewater sludge management: a brazilian approach. In: LeBLANC, R. J.; MATTHEWS, P.; RICHARD, R. P. (Eds.). Global atlas of excreta, wastewater sludge, and biosolids management: moving forward the sustainable and welcome uses a global resource. Nairobi: UN-HABITAT, 2008.

BEECHER, N. Overview: moving forward the sustainable and welcome uses a global resource. In: LeBLANC, R. J.; MATTHEWS, P.; RICHARD, R. P. (Eds.). Global atlas of excreta, wastewater sludge, and biosolids management: moving forward the sustainable and welcome uses a global resource. Nairobi: UN-HABITAT, 2008.

BIOCICLO. Estudo de viabilidade para a instalação e operação de centrais de tratamento de lodo na bacia PCJ. Americana: Consórcio PCJ, 2012.

BRASIL. Lei $n^{0}$ 12305, de 02 de agosto de 2010. Institui a Política Nacional de Resíduos Sólidos; altera a Lei no 9.605, de 12 de fevereiro de 1998; e dá outras providências. Diário Oficial [da] União, Brasília, DF, 03 ago. 2010.

COMPANHIA BRASILEIRA DE PROJETOS E EMPREENDIMENTOS - COBRAPE. Plano das bacias hidrográficas dos rios Piracicaba, Capivari e Jundiaí 2010 a 2020 - relatório final. São Paulo, 2011. 815 p.

CONAMA. Resolução no 375, de 29 de agosto de 2006. Define critérios e procedimentos, para o uso agrícola de lodos de esgoto gerados em estações de tratamento de esgoto sanitário e seus produtos derivados, e dá outras providências. Diário Oficial [da] União, Brasília, DF, 30 ago. 2006.

CLARKE, B. O.; SMITH, S. R. Review of 'emerging' organic contaminants in biosolids and assessment of international research priorities for the agricultural use of biosolids. Environment International, v. 37, n. 1, p. 226-247, 2011. http://dx.doi.org/10.1016/j.envint.2010.06.004

KELESSIDIS, A.; STASINAKIS, A. S. Comparative study of the methods used for treatment and final disposal of sewage sludge in European countries. Waste Management, v. 32, p. 1186-1195, 2012. http://dx.doi.org/10.1016/j.wasman.2012.01.012

LU, Q.; HE, Z. L.; STOFFELLA, P. J. Land application of biosolids in the USA: a review. Applied and Environmental Soil Science, v. 2012, Article ID 201462, 11 p., 2012. http://dx.doi.org/10.1155/2012/201462

MARIN, L. M. K. S.; BITTENCOURT, S.; ANDREOLI, C. V.; CARAFINI, C.; LIMA, M. R.; SERRAT, B. M. et al. Determinação da taxa de aplicação máxima anual de lodo de esgoto higienizado por processo alcalino em solos da região metropolitana de Curitiba. Engenharia Sanitária e Ambiental, v. 15, n. 2, p. 113-118, 2010. http://dx.doi.org/10.1590/S1413-41522010000200003

MURRAY, A.; HORVATH, A.; NELSON, K. L. Hybrid life-cycle environmental and cost inventory of sewage sludge treatment and end-use scenarios: a case study from China. Environmental Science \& Technology, v. 42, p. 3163-3169, 2008. http://dx.doi.org/10.1021/es702256w 
PASDA, N.; PANICHSAKPATANA, S.; LIMTONG, P.; OLIVER, R.; MONTAGE, D. Evaluation of bangkok sewage sludge for possible agricultural use. Waste $\begin{array}{llllll}\text { Management \& } & \text { Research, v. 24, p. 167-174, }\end{array}$ http://dx.doi.org/10.1177/0734242X06063347

PEGORINI, E. S.; ANDREOLI, C. V., SOUZA, M. L. P.; FERNANDES, F. DOETZER, B; FERREIRA, A. C. Produção e disposição final de lodo de esgoto na reciclagem agrícola da região metropolitana de Curitiba - PR. In: SIMPÓSIO SOBRE BIOSSÓLIDOS NO ÂMBITO DO MERCOSUL, 3., São Paulo, 2003. Anais... Rio de Janeiro: ABES; AIDIS, 2003. 1 CD-ROM.

SINGH, R. P.; AGRAWAL, M. Potential benefits and risks of land application of sewage sludge. Waste Management, v. 28, p. 347-358, 2008.

http://dx.doi.org/10.1016/j.wasman.2006.12.010

SOUZA, M. L. P.; RIBEIRO, A. N.; ANDREOLI, C. V.; SOUZA, L. C. P.; BITTENCOURT, S. Aptidão das terras do Estado do Paraná para a disposição final de lodo de esgoto. Revista DAE, n. 177, 2008. http://dx.doi.org/10.4322/dae.2014.012 